\title{
Electrospinning as an Important Tool for Fabrication of Nanofibers for Advanced Applications-a Brief Review
}

\author{
Merin Sara Thomas, ${ }^{a}$ Prasanth K. S. Pillai, ${ }^{,}, b, c$ Scott C. Farrowc, Laly A. Pothan, ${ }^{*, b}$ and Sabu Thomas ${ }^{b}$ \\ ${ }^{a}$ Department of Chemistry, Mar Thoma College, Thiruvalla, Kerala, India \\ ${ }^{b}$ IIUCNN, Mahatma Gandhi University, Kottayam, Kerala, India \\ ${ }^{c}$ Trent University, 1600 West Bank Drive, ON, Canada
}

Email: prasanthpillai42@gmail.com (P. K. S. P.); lapothan@gmail.com (L. A. P.)

\begin{abstract}
Nanomaterials are attracting renewed interest due to their novel properties, which are not seen in their conventional micro state counterparts. They are used in advanced applications in the fields of catalysis, medicine, electronics, optics and membranes. Electrospinning is one of the simplest and cheapest methods to make nano-porous polymer membranes, and these offer a large surface area-to-volume ratio, high porosity and small pore size. These electrospun nonwoven mats could be employed in myriad applications ranging from filtration, sensors, electrode materials, drug delivery, cosmetics, and tissue scaffolding. This technique can introduce novel functional characteristics, and hence by changing the basic experimental set up, solvent, solution and polymer characteristics can alter the composition, morphology, and porosity of the processed material. The unique structural and functional characteristics inherited at submicron to nanoscale dimensions via electrospinning makes it an attractive technique for advanced industrial applications.
\end{abstract}

Keywords electrospinning, biomedical, nanofibers, polylactic acid, chitosan

\section{Introduction}

Nanoscale material has great potential in fields ranging from biology, engineering, and the aerospace industry. Nanostructures like nanofibers can be produced in several ways and are of great interest due to their large surface to volume ratio, affordability, and ease of production. Numerous methodologies have been established to generate nanofibrous materials including drawing, phase separation, template synthesis, self-assembly, and electrospinning. Of these, electrospinning has been identified as one of the most popular methods for obtaining nanofibers due to its simplicity and ability to produce an array of versatile materials. Anton $(1938)^{[1]}$ was the first to patent the electrospinning process, which uses a high electric field for the creation of nanofibers. Since its discovery, research in the area of electrospinning has increased greatly due to the emergence of nanotechnology and the demand for nanofibrous material. In this regard, electrospinning is the most widely used, simple and versatile method for fabrication of nanofibers. In particular, electrospinning is an excellent technique for the creation of layered, porous nanofiber structures, which can be costly and/or difficult to produce using other methods. Much of the electrospinning research today is conducted to understand how to make different nanoscale polymers and what process parameters control the output of products generated using this process.

Electrospinning has been of interest for many decades. Gilbert $^{2]}$ determined that a spherical drop of water could be drawn into a conical shape when an electric charge was applied. When a polymer dissolved in a spherical droplet is introduced, a solid fiber can be formed by the generated electrical field. Similarly, nanofibers are formed by continuous stretching, due to the electrostatic repulsion between charged nanofibers during evaporation of the solvent. ${ }^{[3]}$ More than 100 different nanofiber polymers have been successfully spun into ultrafine structures using this technique and have been employed in various applications.

The potential application of such materials in cell biology and tissue engineering has resulted in a large number of synthetic, biodegradable polymers being electrospun into nanofibers, including poly(caprolactone) $(\mathrm{PCL}),{ }^{[4]}$ poly(lactic acid) (PLA), ${ }^{[4,5]}$ poly(glycolic acid) (PGA), ${ }^{[6]}$ and poly(lactide-coglycolide) (PLGA) ${ }^{[7]}$ In addition to these synthetic polymers, natural biopolymers such as silk fibroin, ${ }^{[8]}$ fibrinogen, ${ }^{[9]}$ dextran, ${ }^{[10]}$ collagen, ${ }^{[11]}$ cellulose ${ }^{[12]}$ alginate ${ }^{[13]}$ and chitosan ${ }^{[14]}$ have been successfully processed by electrospinning. Compared to their synthetic counterparts, naturally derived polymers have good biocompatibility; however, their processability is generally poor by comparison.

Many functional polymers are not suitable for electrospinning due to their molecular weight and/or solubility. However, one of the most effective strategies for solving this problem is to create polymer blends that are well-suited for electrospinning. ${ }^{[15]}$ This approach may not only reduce the potential problem of cytotoxicity, as a result of using a chemical cross-linking reagent, but also provides a well-designed solution for overcoming the shortcomings of synthetic and natural polymers.

\section{Electrospinning: Principle and Set Up}

Electrospinning is a simple, low cost method used for the production of continuous layered nanofibers that overcomes many of the limitations of other fabrication techniques like molecular self-assembly, template synthesis, drawing or thermally induced phase separation. The basic instrument configuration of electrospinning includes a high voltage power supply, a capillary tip or nozzle, and a grounded collection plate that is separated from the nozzle at an optimized distance (Figure 1). In this technique, a mat of solid polymer fibers are prepared from a polymer solution by applying an electric field. The basic principle behind this process is that when the 


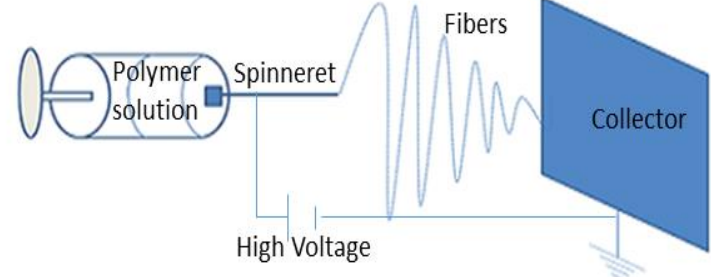

Figure 1 The basic electrospinning instrumental set up. ${ }^{[18]}$

electrostatic repulsive force exceeds the surface tension of the polymer solution, a charged jet of polymer solution is electrically pulled towards the collector plate and deposited as a randomly oriented, non-woven fiber mat. ${ }^{[16]}$ Thus, the morphology of the fibers have smooth or beaded structures, ${ }^{[17]}$ however, characteristics like surface morphology, diameter, porosity, hydrophobicity, etc., can be tailored through polymer solution properties, processing and environmental conditions.

\section{Factors Affecting Electrospinning}

\section{Effect of solvents}

Solvent selection is very important for electrospinning process as it influences success of process and physical characteristics of nanofibers. For example, the homogeneity of polymer solution is of crucial importance for obtaining uniform fibrous mats. Wannatong et al. ${ }^{[19]}$ reported that the solubility parameters of polymer and solvent are predictive of polystyrene (PS) nanofiber morphology. Specifically, they found unwanted beaded structures on PS nanofibers when solubility parameters of PS and solvent were not optimal. ${ }^{[19]}$ Similarly, Arrieta et al. ${ }^{[20]}$ reported that chitosan particles demonstrate a beaded morphology when organic solvent mixtures are used with low chitosan solubility. Natarajan et al. ${ }^{[21]}$ studied the pore formation mechanism within PLA fibers and found that the solubility parameter plays a key role, whereby the thermodynamic instability of a polymer solution will lead to the formation of pores. This occurs through the formation of a solvent rich phase and solvent poor phase, and it is the solvent rich phase that is responsible for the formation of pores. ${ }^{[1,22]}$

Boiling point plays a major role in the electrospinning process. The volatility rate of solvents with very high boiling points is low and as such, it is difficult to evaporate the solvent fully before the polymer jet reaches the collector. As a result, nanofibers become flattened with a ribbon like morphology. ${ }^{[23]}$ On the other hand, use of solvents with prohibitively low boiling points and high solvent volatility rates might cause rapid evaporation at the needle tip, thereby causing needle blockage and disruption of the process. ${ }^{[24]}$ For example, Jahangir et al. ${ }^{[25]}$ reported that the polymeric jet of PLA in dimethylformamide (DMF) and dimethylacetamide (DMAc) did not permit adequate drying time during flight to the collector, and this was attributed to a high solvent boiling point.

Solvent volatility is another important factor affecting pore formation. Yang et al. ${ }^{[26]}$ reported isolated pores on the surface of PLA fibers when chloroform (boiling point: $61.3^{\circ} \mathrm{C}$ ) was used as the solvent, while polymer fibers with smooth surface structures were obtained when trifluoroethanol was used (TFE, boiling point: $103^{\circ} \mathrm{C}$ ). They suggested this was the result of the thermally induced phase separation phenomenon and attributed that the temperature of fibrous surface had decreased due to sudden evaporation of chloroform. As a result, the atmospheric moisture condensed on the polymer surface, leaving behind an imprint in the form of pores.

\section{Solvent dielectric constant}

The electrostatic energy required to ionize a polymer solution is inversely proportional to dielectric constant of solution. Hence by using solvents with high dielectric constants, the degree of polymer solution dissociation increases, and thus, free charge density will be higher leading to improved conductivity. The dielectric constant and solubility parameter are in direct agreement. Jahangir et al. ${ }^{[25]}$ proposed that by increasing dielectric constant and dipole moment of solvent, nanofiber productivity could be increased. Torres-Giner et al. ${ }^{[27]}$ studied the hindering of electrospinning process of chitosan when it is dissolved in the high dielectric solvent trifluoro acetic acid (TFA). This is due to repulsive forces between the polycations along the chitosan polymer chain, which restrict sufficient chain entanglement.

\section{Effect of solution properties}

Solution properties are interdependent whereby if we change one of the solution properties like polymer concentration, surface tension and viscosity also change. The formation of nanofibers in the electrospinning process is highly dependent on polymer concentration as this effects viscosity, surface tension and conductivity. In this regard, one of the important conditions for electrospinning is sufficient chain entanglement, and this can only be achieved by having a threshold concentration of the polymer. The diameter of nanofiber as well as its surface morphology depend highly on solution viscosity. A polymer solution with low viscosity leads to a beaded morphology as a result of high surface tension. By comparison, high viscosity leads to the formation of narrow and uniform fibers, while even higher viscosity leads to fibers with very large diameters, which inhibits proper electrospinning. Therefore, an optimum solution viscosity is required for adequate electrospinning to occur.

Polymer molecular weight is an important criterion for the electrospinning process. Whereas high molecular weight polymers provide sufficient chain entanglement leading to an adequate polymer solution viscosity, which is favorable to the electrospinning process. Low molecular weight compounds can be difficult to electrospin due to their lower viscosity and chain entanglement. ${ }^{[28]}$ The relationship between viscosity and surface tension of polymer solutions of chitosan at variable molecular weights was studied, and the solutions containing higher molecular weight chitosan exhibited lower surface tension and higher viscosity compared to solutions containing identical chitosan concentrations that were comprised of lower and medium molecular weight chitosan. ${ }^{[27]}$ These properties rendered the electrospinning process more successful, resulting in bead-free nanofibers. Mendes et al. ${ }^{[2]}$ studied the effect of molecular weight on nanofiber morphology of an electrospun chitosan/phospholipid hybrid and found that the average diameter of nanofibers increased with molecular weight, the degree of chitosan deacetylation, and phospholipid content. In some cases, electrospinning is not always dependent upon high molecular weight polymers. For example, McKee et al. ${ }^{[30]}$ successfully implemented intermolecular interaction between oligomeric phospholipids from lecithin for fabrication of electrospun mats.

The surface tension of polymer solution is fundamental parameter, which determines electrospinnability of the solution. To obtain bead free nanofibers, it is necessary to keep the surface tension at a minimum, which helps electrospinning occur at a low electric field. Alternatively, very high surface tension of a polymer solution leads to electrospraying rather 
than electrospinning. In general, the solution surface tension depends on two parameters: (i) selection of solvent, and (ii) concentration of polymer. Usually, the upper and lower boundary of electrospinning is determined by surface tension.

The electrospinning process starts only when the polymeric solution possesses conductivity. Solution conductivity depends on the polymer, solvent and presence of ionizable salts. The two parameters affected by the solution conductivity are surface charge density and tangential electric field, of which both determine the Taylor cone formation and the ejected linear jet. The fiber morphology is also affected by conductivity of polymer solution. High conductivity of polymer solution results in a significant decrease in the diameter of electrospun nanofibers, whereas with low conductivity of the solution results in insufficient jet elongation by electrostatic forces leading to uniform fibers and bead formation.

Biopolymers like chitosan, gelatins, etc., are polyelectrolytic in nature. But their fiber forming ability is very low due to high charge density. The conductivity of these polymers can be improved by the addition of salts like $\mathrm{KH}_{2} \mathrm{PO}_{4}, \mathrm{NaH}_{2} \mathrm{PO}_{4}$ and $\mathrm{NaCl}$, which helps to produce beadless fibers with relatively smaller diameters. This use of salt additives can be employed for many polymers such as poly (ethylene oxide) ( $\mathrm{PEO}^{[17]}$ ), collagen type I-PEO, ${ }^{[31]}$ poly(vinyl alcohol) $\left(\mathrm{PVA}^{[32]}\right)$, polyacrylic acid $\left(\mathrm{PAA}^{[33]}\right)$, polyamide- $6^{[34]}$ and others. With the use of salts, the uniformity of fibers increases, and bead formation decreases.

\section{Effect of Process Parameters}

As in the case of solution properties, many of the parameters are interconnected and each may affect the process in multiple and sometimes contradictory ways, giving rise to different phenomena and different outcomes regarding electrospinnability and fiber morphology.

The electrospinning process starts only after the polymer solution attains a threshold voltage, whereas the behavior of polymer solution towards applied voltage is controversial. Shao et $a l .{ }^{[35]}$ studied the morphology of electrospun poly(vinylidene fluoride) nanofiber mats with varying voltage. They observed that uniform, beadless nanofibers were obtained when the applied voltage was set in the range of $9-21 \mathrm{kV}$ and fiber diameter decreased with increased voltage. According to Shao et al., ${ }^{[35]}$ the decrease in fiber diameter arises as a consequence of higher electrostatic force (applied voltage) to stretch the jet and filament during electrospinning. By contrast, very high applied voltage results in fibers with larger diameters. ${ }^{[36]} \mathrm{Li}$ et $a{ }^{\left[{ }^{[366]}\right.}$ found that low-voltage (low electric field) operation provides a potential mild processing route for biological elements.

The fiber diameter and the flow rate are in close agreement in an electrospinning process. Usually, a lower flow rate is recommended, providing enough time for solvent evaporation, leading to uniform, homogeneous fibers. With increased flow rate, the fiber diameter as well as the fiber porosity increases. Tang et al. ${ }^{[37]}$ proved this theoretically. With high flow rate, the polymer jet does not permit enough drying time, and hence beaded structures are formed.

For the formation of smooth, uniform nanofibers, it is necessary to keep a critical distance between the needle tip and collector. It has been observed that if the distance between needle tip to collector is too close, nanofibers become flat. Whereas if the distance is large, the fiber surface becomes circular. ${ }^{[38]}$ Type, size and shape of the collector are important aspects in an electrospinning process. In electrospinning, usually a metallic conductive collector is used. The simplest most commonly used collector is a square/rectangular shaped aluminum plate/foil. ${ }^{[18]} A$ variety of modified forms of collectors were used to avoid difficulty in transferring of collected fibers and with the need for aligned fibers for various applications. The variety of collectors include conductive paper, conductive cloth, wire mesh, pin, parallel or grided bar, rotating rod, rotating wheel. ${ }^{[18]}$ Liquid non-solvent such as a methanol coagulation bath $^{[39]}$ and others are also common types of modern collectors. The main collectors used for electrospinning are presented in Figure 2.

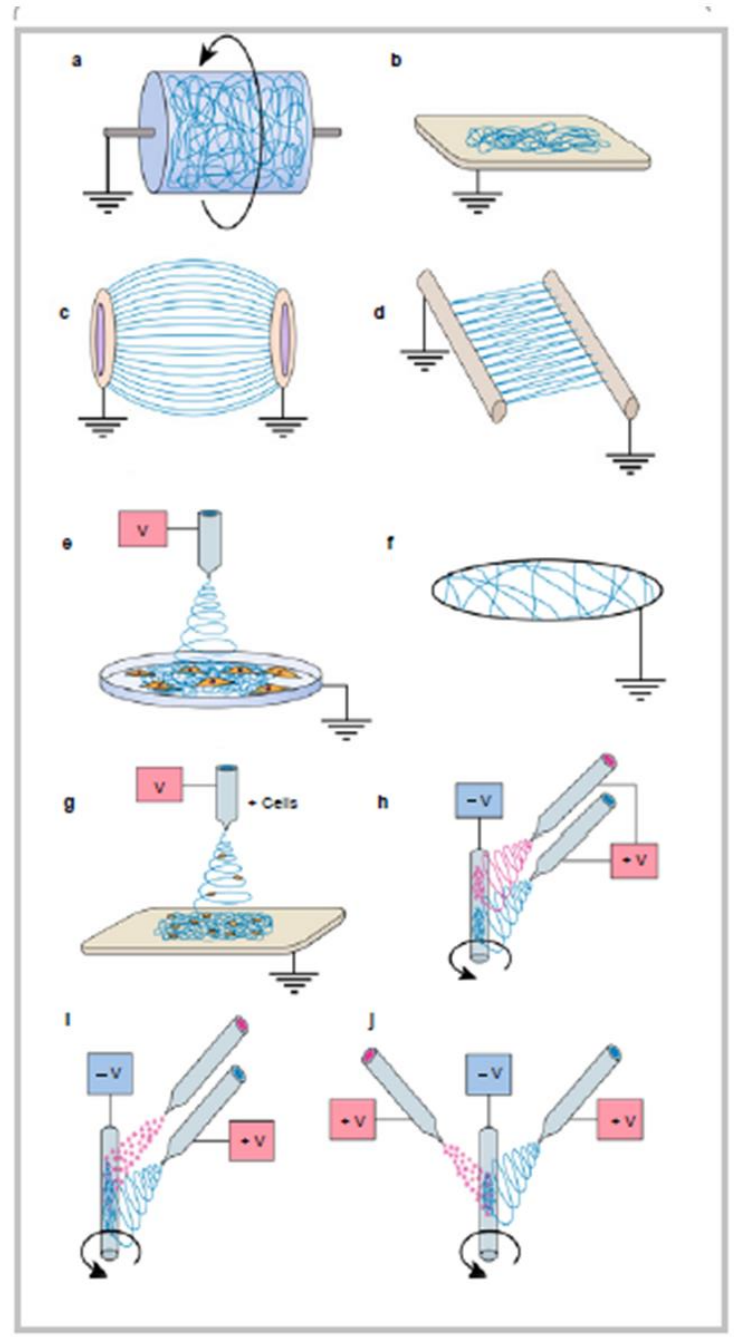

Figure 2 Electrospinning collecting schemes. (A) Rotating single ground, (B) single ground, (C) dual ring, (D) dual bar, (E) electrospinning in vitro onto cells, $(F)$ single horizontal ring, $(G)$ electrospinning cells with polymer, $(\mathrm{H})$ dual spinneret electrospinning (with second pink fibers), (I) electrospinning/electrospraying with parallel, and $(\mathrm{J})$ perpendicular spinnerets. ${ }^{[40]}$

\section{Effect of Environmental Parameters}

In addition to electrospinning and solution parameters, ambient parameters such as temperature and humidity affect the electrospinning process. Humidity can control the solvent evaporation rate. For example, Cheng et al. ${ }^{[41]}$ studied the effect of humidity on the fabrication of three dimensional cellulose acetate nanofiber stacks and reported that the presence of water molecules at higher relative humidity decreased the number of excess charges on the electrospinning jet. As a result, the polymer jet experiences a less intense electric field 
leading to the reduced elongation of the fiber and larger fiber diameter. Alternatively, low humidity results in a faster solvent evaporation rate of a volatile solvent leading to fibers with a thinner diameter. At extremely low humidity, clogging is encountered at the needle tip, thus inhibiting the electrospinning process. Humidity can control the porous structure of nanofiber surface by phase separation behaviour. Zaarour et al. ${ }^{[42]}$ reported the pore formation behavior in electrospun fibers at varying relative humidity. They found that fibers with a smooth surface and solid interior were observed at low relative humidity and macro-porous fibers, with interior pores, were observed at high relative humidity due to the combination of temperature induced phase separation behavior and vapour induced phase separation.

The average diameter of electrospun fibers is affected by the change in temperature. In particular, the morphology of fibers as a result of temperature occurs in two ways: (1) solvent evaporation decreases exponentially with decreasing temperature leading to elongation of the polymer jet and a reduction in fiber diameter, (2) increase in temperature leads to a decrease in polymer solution viscosity resulting in thinner fibers. Both responses result in nanofibers with decreased diameter. ${ }^{[43]}$

\section{Core/shell Electrospinning}

One of the key components in the core/shell or coaxial electrospinning setup is a compound spinneret consisting of two (or more) small-diameter capillary tubes with one located inside the other. ${ }^{[40]}$ The basic experimental setup is shown in Figure 3. It is essentially the same as that of a conventional electrospinning setup, except for the introduction of an inner capillary tube or needle. The inner capillary tube, also acting as an electrode for the spinning drops, is connected to an electrical potential of several to tens of kilovolts relative to the ground electrode (the collector). The inner flow rate is adjusted by a syringe pump, whereas the outer tube is opened to atmosphere. At a certain range of applied electrical potential and flow rate, a structured Taylor cone is formed at the exit of the coaxial tubes with an outer meniscus surrounding that of the inner tube. A liquid thread is issued from the vertex of each of the two menisci, giving rise to a compound jet. After evaporation of the solvents during the course of jet flying, a core-shell structured, bi-component composite nanofiber is produced. Core-shell fibers made of bioresorbable fibers are useful encapsulation agents, in which the biologically active molecules are incorporated within the fibers.

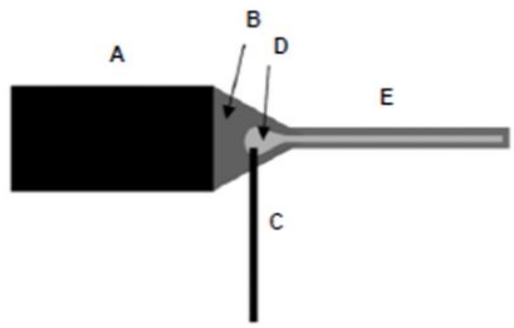

Figure 3 Schematic of the alternative set-up for co-axial electrospinning. (A) Large capillary carrying sheath solution, (B) Taylor cone comprised of sheath solution, (C) small capillary carrying core solution, inserted directly into secondary Taylor cone, (D) secondary Taylor cone formed co-axially inside the sheath Taylor cone, $(\mathrm{E})$ co-axial jet. ${ }^{[40]}$

\section{Advantages of Electrospun Nanofibers}

The library of nanofibers produced by electrospinning have a wide range of applications due to unique material morphologies, aspect ratios and inter/intra fibrous porosity (Figure 4). As such, the potential applications of electrospun fibers range from biomedical applications (tissue engineering, wound healing, drug delivery and enzyme immobilization), environmental protection (water purification and air filtration), affinity membranes, nanobiosensors, electronic/optical, food science (packaging applications, preparation of edible films) and protective clothing fields, etc. Moreover, electrospinning is a simple, cost effective and versatile technique for fabrication of highly sought-after nanofibers.

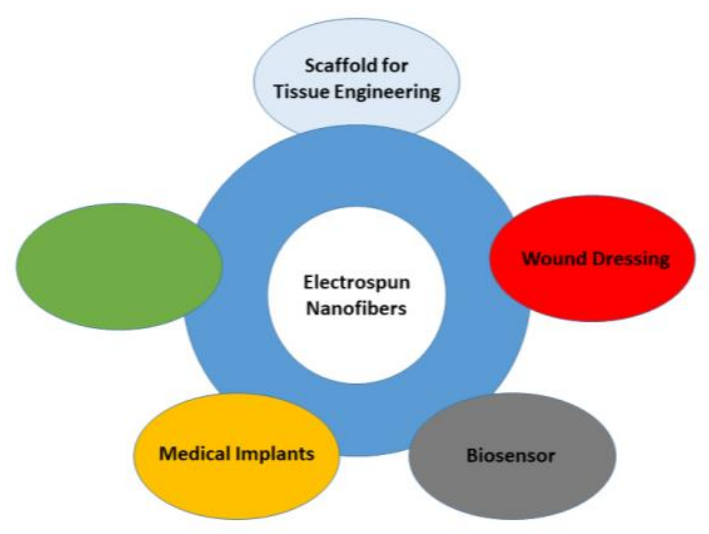

Figure 4 Applications of electrospun nanofibers. ${ }^{[4]}$

\section{Miscellaneous Applications}

The use of electrospinning for materials in tissue engineering, wound healing and drug delivery has recently received focused attention $\left(\mathrm{PCL}^{[4 \mathrm{a}-4 \mathrm{c}, 45]}\right)$. Electrospinning provides a simpler and more cost-effective means to produce fibrous scaffolds with an inter-connected pore structure and fiber diameter in the sub-micron range. Choices in materials include both natural and synthetic (biodegradable and nondegradable) materials, as well as hybrid blends, which can provide an optimal combination of mechanical and biomimetic properties. By varying the previously discussed processing and solution parameters, the fiber orientation (aligned vs. random) and porosity/pore size (cell infiltration) of the electrospun scaffolds can be controlled and optimized for each application. After fabrication, the surface of scaffold can be modified with high density of bioactive molecules due to the relatively high scaffold surface area. Due to the flexibility in material selection as well as the ability to control scaffold properties, electrospun scaffolds have been employed in a number of different tissue applications including: vascular, bone, neural, and tendon/ ligament.

The microfibrous and nanofibrous structures obtained via the electrospinning process escalated the demand of such materials for making wound-healing polymer devices. This method provides nonwoven textile material with desirable physical properties with some even showing cytocompatibility and cell-like behaviour with normal human keratinocytes and fibroblasts placed onto electrospun silk fibroin nanofibrous membranes. Researchers have investigated the wound-healing properties of electrospun type I collagen fiber mats in mice and found that healing was better with nanofiber mats than with conventional wound care, especially in the early stages of the 
healing process. Apart from electrospun collagen, silk and polyurethane fibers are also used in wound dressings.

Electrospinning affords great flexibility in selecting materials for drug delivery applications. As the drug and carrier materials can be mixed together for electrospinning of nanofibers, the likely modes of the drug in the resulting nanostructed products are: (1) drug as particles attached to the surface of the carrier which is in the form of nanofibers, (2) both drug and carrier are in a nanofibrous form, hence the end product will be two kinds of nanofibers with an interlaced structure, (3) the blend of drug and carrier materials integrated into one kind of fibers containing both components, and (4) the carrier material is electrospun into a tubular form in which the drug particles are encapsulated. The modes (3) and (4) may be preferred. Additionally, due to the flexibility in material selection, a number of drugs can be delivered including: antibiotics, anticancer drugs, proteins, and DNA. Using the various electrospinning techniques, a number of different drug loading methods can also be utilized: coatings, embedded drug, and encapsulated drug (coaxial and emulsion electrospinning). These techniques can be used to give finer control over drug release kinetics.

It has been realized that electrospinning is rising to the challenge of providing solutions for the removal of harmful particles in the submicron ranges. Generally, due to the very high surface area to volume ratio and the resulting high surface cohesion, tiny particles of the order of $<0.5 \mathrm{~mm}$ can be easily trapped in the electrospun nanofibrous structured filters and this improves the filtration efficiency. Electrospun non-woven mats have successfully been developed into high-performance air filters. The nanofiber membrane shows an extremely effective removal (appx. 100\% rejection) of airborne particles with diameters between $1 \mu \mathrm{m}$ and $5 \mu \mathrm{m}$ not only by the physical entrapment mechanism but also by the electrokinetic capture in the air filter.

\section{Conclusions and Perspectives}

Electrospinning is an attractive approach for polymer biomaterial processing, providing an opportunity to control morphology, porosity, and composition using relatively unsophisticated equipment. In addition, this relatively simple technique creates materials with unique properties with structural and functional characteristics such as submicron to nanoscale dimensions, high aspect ratio, inter/intra fibrous porosity and high encapsulation efficiency for bioactive compounds. This technique can be used to finely control polymer architecture making it an excellent choice for advanced structural, environmental and biomedical applications.

\section{Acknowledgements}

The authors wish to thank the Nanoscience and Nanotechnology department, M. G. University for their support.

\section{Author Contributions}

Merin Sara Thomas and Prasanth K. S. Pillai wrote and organized this manuscript. The remaining authors contributed by collecting relevant literatures, revision and editing.

\section{Conflict of Interest}

The authors declare no conflict of interest.

Copyright (C) 2021 Merin Sara Thomas, Prasanth K. S. Pillai, Scott C. Farrowc, Laly A. Pothan, and Sabu Thomas. This article is an open access article distributed under the terms and conditions of the Creative Commons Attribution (CC BY) license (http://creativecommons.org/ licenses/by/4.0/). The use, distribution or reproduction in other forums is permitted, provided the original author(s) or licensor are credited and that the original publication in this journal is cited, in accordance with accepted academic practice. No use, distribution or reproduction is permitted which does not comply with these terms.

\section{References}

[1] Anton, F. Method and apparatus for spinning. 1939, Google Patents.

[2] Gilbert, W. De magnete, magneticisque corporibus, et de magno magnete tellure. 1956, Petrvs Short.

[3] Doshi, J.; Reneker, D. H. Electrospinning process and applications of electrospun fibers. J. Electrostat. 1995, 35, 151-160.

[4] (a) Komur, B.; Bayrak, F.; Ekren, N.; Eroglu, M.; Oktar, F. N.; Sinirlioglu, Z.; Yucel, S.; Guler, O.; Gunduz, O. Starch/PCL composite nanofibers by co-axial electrospinning technique for biomedical applications. Biomed. Eng. Online 2017, 16, 1-13; BMochane, M. J.; Motsoeneng, T. S.; Sadiku, E. R.; Mokhena, T. C.; Sefadi, J. S. Morphology and properties of electrospun PCL and its composites for medical applications: A mini review. Appl. Sci. 2019. 9, 2205; (b) Ren, K.; Wang, Y.; Sun, T.; Yue, W.; Zhang, H. Electrospun $\mathrm{PCL} /$ gelatin composite nanofiber structures for effective guided bone regeneration membranes. Mater. Sci. Eng. $C$ 2017, 78, 324-332; (c) Liu, W.; Dong, Y.; Liu, D.; Bai, Y.; Lu, X. Polylactic acid (PLA)/cellulose nanowhiskers (CNWs) composite nanofibers: microstructural and properties analysis. J. Compos. Sci. 2018, 2, 4 .

[5] (a) Meyva-Zeybek, Y.; Kaynak, C. Electrospinning of PLA and PLA/POSS nanofibers: Use of Taguchi optimization for process parameters. J. Appl. Polym. Sci. 2021, 138, 49685; (b) Perumal, G.; Pappuru, S.; Chakraborty, D.; Nandkumar, A. M.; Chand, D. K.; Doble, M. Synthesis and characterization of curcumin loaded PLA-Hyperbranched polyglycerol electrospun blend for wound dressing applications. Mater. Sci. Eng. C 2017. 76, 1196-1204; (c) Thomas, M. S.; Pillai, P. K.; Faria, M.; Cordeiro, N.; Kailas, L.; Kalarikkal, N.; Thomas, S.; Pothen, L. A. Polylactic acid/nano chitosan composite fibers and their morphological, physical characterization for the removal of cadmium (II) from water. J. Appl. Polym. Sci. 2020, 137, 48993.

[6] (a) de la Cruz, L. I. S.; Rodríguez, F. J. M.; Velasco-Santos, C.; Martínez-Hernández, A.; Gutiérrez-Sánchez, M. Hydrolytic Degradation and Morphological Characterization of Electrospun Poly (glycolic acid)[PGA] Thin Films of Different Molecular Weights Containing $\mathrm{TiO}_{2}$ Nanoparticles. J. Polym. Res. 2016, 23, 113; (b) Díez-Pascual, A. M.; Díez-Vicente, A. L. Multifunctional poly (glycolic acid-co-propylene fumarate) electrospun fibers reinforced with graphene oxide and hydroxyapatite nanorods. J. Mater. Chem. B 2017, 5, 4084-4096.

[7] (a) Chen, Y.-P.; Liu, H.-Y.; Liu, Y.-W.; Lee, T.-Y.; Liu, S.-J. Determination of electrospinning parameters' strength in Poly $(D$, L)-lactide-co-glycolide micro/nanofiber diameter tailoring. J. Nanomater. 2019, 2019; (b) Mirzaei, A.; Saburi, E.; Islami, M.; Ardeshirylajimi, A.; Omrani, M. D.; Taheri, M.; Moghadam, A. S.; Ghafouri-Fard, S. Bladder smooth muscle cell differentiation of the human induced pluripotent stem cells on electrospun Poly (lactide-co-glycolide) nanofibrous structure. Gene 2019, 694, 26-32.

[8] (a) Farokhi, M.; Mottaghitalab, F.; Reis, R. L.; Ramakrishna, S.; Kundu, S. C. Functionalized silk fibroin nanofibers as drug carriers: Advantages and challenges. J. Controlled Release 2020, 321, 324-347; (b) Karatepe, U. Y.; Ozdemir, T. Improving mechanical and antibacterial properties of PMMA via polyblend electrospinning with silk fibroin and polyethyleneimine towards dental applications. Bioact. Mater. 2020, 5, 510-515; (c) Kishimoto, Y.; Morikawa, H.; Yamanaka, S.; Tamada, Y. Electrospinning of silk fibroin from all aqueous solution at low concentration. Mater. Sci. Eng. C 2017, 73, 498-506. 
[9] (a) Mirzaei-Parsa, M. J.; Ghanizadeh, A.; Ebadi, M. T.; Faridi-Majidi, R. An alternative solvent for electrospinning of fibrinogen nanofibers. Bio-Med. Mater. Eng. 2018, 29, 279-287; (b) Sharpe, J. M.; Lee, H.; Hall, A. R.; Bonin, K.; Guthold, M. Mechanical Properties of Electrospun, Blended Fibrinogen: PCL Nanofibers. Nanomaterials 2020, 10, 1843.

[10] (a) Fathi, M.; Nasrabadi, M. N.; Varshosaz, J. Characteristics of vitamin E-loaded nanofibres from dextran. Int. J. Food Prop. 2017, 20, 2665-2674; (b) Malini, R. I.; Lesage, J.; Toncelli, C.; Fortunato, G.; Rossi, R. M.; Spano, F. Crosslinking dextran electrospun nanofibers via borate chemistry: Proof of concept for wound patches. Eur. Polym. J. 2019, 110, 276-282; (c) Moydeen, A. M.; Padusha, M. S. A.; Thamer, B. M.; Al-Enizi, A. M.; El-Hamshary, H.; El-Newehy, M. H. Single-nozzle core-shell electrospun nanofibers of pvp/dextran as drug delivery system. Fibers Polym. 2019, 20, 2078-2089.

[11] (a) Law, J. X.; Liau, L. L.; Saim, A.; Yang, Y.; Idrus, R. Electrospun collagen nanofibers and their applications in skin tissue engineering. J. Tissue Eng. Regen. Med. 2017, 14, 699-718; (b) Nune, S. K.; Rama, K. S.; Dirisala, V. R.; Chavali, M. Y. Electrospinning of Collagen Nanofiber Scaffolds for Tissue Repair and Regeneration. In Nanostructures for Novel Therapy. 2017, Elsevier, pp. 281-311; (c) Wakuda, Y.; Nishimoto, S.; Suye, S.-i.; Fujita, S. Native collagen hydrogel nanofibres with anisotropic structure using core-shell electrospinning. Sci. Rep. 2018, 8, 1-10.

[12] (a) Dizge, N.; Shaulsky, E.; Karanikola, V. Electrospun cellulose nanofibers for superhydrophobic and oleophobic membranes. $J$. Membr. Sci. 2019, 590, 117271; (b) Jahanbaani, A. R.; Behzad, T.; Borhani, S.; Darvanjooghi, M. H. K. Electrospinning of cellulose nanofibers mat for laminated epoxy composite production. Fibers Polym. 2016, 17, 1438-1448.

[13] (a) Mokhena, T. C.; Mochane, M. J.; Mtibe, A.; John, M. J.; Sadiku, E. R.; Sefadi, J. S. Electrospun alginate nanofibers toward various applications: A review. Materials 2020, 13, 934; (b) Taemeh, M. A.; Shiravandi, A.; Korayem, M. A.; Daemi, H. Fabrication challenges and trends in biomedical applications of alginate electrospun nanofibers. Carbohydr. Polym. 2020, 228, 115419.

[14] (a) Bayat, S.; Amiri, N.; Pishavar, E.; Kalalinia, F.; Movaffagh, J.; Hashemi, M. Bromelain-loaded chitosan nanofibers prepared by electrospinning method for burn wound healing in animal models. Life Sci. 2019, 229, 57-66; (b) Tao, F.; Cheng, Y.; Shi, X.; Zheng, H.; Du, Y.; Xiang, W.; Deng, H. Applications of chitin and chitosan nanofibers in bone regenerative engineering. Carbohyd. Polym. 2020, 230, 115658.

[15] (a) Grimmelsmann, N.; Homburg, S. V.; Ehrmann, A. Electrospinning Chitosan Blends for Nonwovens with Morphologies between Nanofiber Mat and Membrane. In IOP Conference Series: Materials Science and Engineering. 2017, IOP Publishing; (b) Samimi Gharaie, S.; Habibi, S.; Nazockdast, H. Fabrication and characterization of chitosan/gelatin/thermoplastic polyurethane blend nanofibers. J. Text. Fibrous Mater. 2018, 1, 2515221118769324

[16] (a) Beachley, V.; Wen, X. Polymer nanofibrous structures: Fabrication, biofunctionalization, and cell interactions. Prog. Polym. Sci. 2010, 35, 868-892; (b) Li, D.; Xia, Y. Electrospinning of nanofibers: reinventing the wheel? Adv. Mater. 2004, 16, 1151-1170.

[17] Fong, H.; Chun, I.; Reneker, D. H. Beaded nanofibers formed during electrospinning. Polymer 1999, 40, 4585-4592.

[18] Bhardwaj, N.; Kundu, S. C. Electrospinning: a fascinating fiber fabrication technique. Biotechnol. Adv. 2010, 28, 325-347.

[19] Wannatong, L.; Sirivat, A.; Supaphol, P. Effects of solvents on electrospun polymeric fibers: preliminary study on polystyrene. Polym. Int. 2004, 53, 1851-1859.

[20] Arrieta, M. P.; López, J.; López, D.; Kenny, J. M.; Peponi, L. Effect of chitosan and catechin addition on the structural, thermal, mechanical and disintegration properties of plasticized electrospun PLA-PHB biocomposites. Polym. Degrad. Stab. 2016, 132, $145-156$.

[21] Natarajan, L.; New, J.; Dasari, A.; Yu, S.; Manan, M. A. Surface morphology of electrospun PLA fibers: mechanisms of pore formation. RSC Adv. 2014, 4, 44082-44088.

[22] Katsogiannis, K. A. G.; Vladisavljević, G. T.; Georgiadou, S. Porous electrospun polycaprolactone fibers: Effect of process parameters. J. Polym. Sci. B Polym. Phys. 2016, 54, 1878-1888.

[23] Lannutti, J.; Reneker, D.; Ma, T.; Tomasko, D.; Farson, D. Electrospinning for tissue engineering scaffolds. Mater. Sci. Eng. C 2007, 27, 504-509.

[24] Pillay, V.; Dott, C.; Choonara, Y. E.; Tyagi, C.; Tomar, L.; Kumar, P.; du Toit, L. C.; Ndesendo, V. M. A review of the effect of processing variables on the fabrication of electrospun nanofibers for drug delivery applications. J. Nanomater. 2013, 2013.

[25] Jahangir, M. A.; Rumi, T. M.; Wahab, A.; Khan, M. I.; Rahman, M. A.; Sayed, Z. B. Poly lactic acid (PLA) fibres: Different solvent systems and their effect on fibre morphology and diameter. Am. J. Chem. 2017, 7, 177-186.

[26] Yang, H.; Wang, L.; Xiang, C.; Li, L. Electrospun porous PLLA and poly (LLA-Co-CL) fibers by phase separation. New J. Chem. 2018, 42, 5102-5108.

[27] Torres-Giner, S.; Ocio, M.; Lagaron, J. Development of active antimicrobial fiber-based chitosan polysaccharide nanostructures using electrospinning. Eng. Life Sci. 2008, 8, 303-314.

[28] Turan, D.; Gibis, M.; Gunes, G.; Baier, S. K.; Weiss, J. The impact of the molecular weight of dextran on formation of whey protein isolate (WPI)-dextran conjugates in fibers produced by needleless electrospinning after annealing. Food Funct. 2018, 9, 2193-2200.

[29] Mendes, A. C.; Moreno, J. S.; Hanif, M.; Douglas, T. E. L.; Chen, M.; Chronakis, I. S. Morphological, mechanical and mucoadhesive properties of electrospun chitosan/phospholipid hybrid nanofibers. Int. J. Mol. Sci. 2018, 19, 2266.

[30] McKee, M. G.; Layman, J. M.; Cashion, M. P.; Long, T. E. Phospholipid nonwoven electrospun membranes. Science 2006, 311, 353-355.

[31] Huang, L.; Bui, N. N.; Manickam, S. S.; McCutcheon, J. R. Controlling electrospun nanofiber morphology and mechanical properties using humidity. J. Polym. Sci. B: Polym. Phys. 2011, 49, 1734-1744.

[32] Zhang, C.; Yuan, X.; Wu, L.; Han, Y.; Sheng, J. Study on morphology of electrospun poly (vinyl alcohol) mats. Eur. Polym. J. 2005, 41, 423-432.

[33] Kim, B.; Park, H.; Lee, S.-H.; Sigmund, W. M. Poly (acrylic acid) nanofibers by electrospinning. Mater. Lett. 2005, 59, 829-832.

[34] (a) Malakhov, S.; Belousov, S.; Shcherbina, M.; Meshchankina, M. Y.; Chvalun, S.; Shepelev, A. Effect of low molecular additives on the electrospinning of nonwoven materials from a polyamide- 6 melt. Polym. Sci. Ser. B 2016, 58, 236-245; (b) Mit-uppatham, C.; Nithitanakul, M.; Supaphol, P. Electrospun Polyamide-6 Nanofibers: Effects of Solvent Systems. In Asian Pacific Confederation of Chemical Engineering Congress Program and Abstracts Asian Pacific Confederation of Chemical Engineers Congress Program and Abstracts. The Society of Chemical Engineers, 2004, Japan.

[35] Shao, H.; Fang, J.; Wang, H.; Lin, T. Effect of electrospinning parameters and polymer concentrations on mechanical-toelectrical energy conversion of randomly-oriented electrospun poly (vinylidene fluoride) nanofiber mats. RSC Adv. 2015, 5, 14345-14350.

[36] (a) Okutan, N.; Terzi, P.; Altay, F. Affecting parameters on electrospinning process and characterization of electrospun gelatin nanofibers. Food Hydrocolloids 2014, 39, 19-26; (b) Li, X.; Li, Z.; Wang, L.; Ma, G.; Meng, F.; Pritchard, R. H.; Gill, E. L.; Liu, Y.; Huang, Y. Y. S. Low-Voltage Continuous Electrospinning Patterning. ACS Appl. Mater. Interfaces 2016, 8, 32120-32131. 
[37] Tang, X.-P.; Na, S. I.; Xu, L.; Liu, H.-Y. Effect of flow rate on diameter of electrospun nanoporous fibers. Therm. Sci. 2014, 18, 1447-1449.

[38] Zhang, D.; Karki, A. B.; Rutman, D.; Young, D. P.; Wang, A.; Cocke, D.; Ho, T. H.; Guo, Z. Electrospun polyacrylonitrile nanocomposite fibers reinforced with $\mathrm{Fe}_{3} \mathrm{O}_{4}$ nanoparticles: Fabrication and property analysis. Polymer 2009, 50, 4189-4198.

[39] Ki, C. S.; Kim, J. W.; Oh, H. J.; Lee, K. H.; Park, Y. H. The effect of residual silk sericin on the structure and mechanical property of regenerated silk filament. Int. J. Biol. Macromol. 2007, 41, 346-353.

[40] Elahi, M. F.; Lu, W.; Guoping, G.; Khan, F. Core-shell Fibers for Biomedical Applications-A Review. J. Biomed. Eng. 2013, 3, 1-4.

[41] Cheng, M.; Qin, Z.; Hu, S.; Yu, H.; Zhu, M. Use of electrospinning to directly fabricate three-dimensional nanofiber stacks of cellulose acetate under high relative humidity condition. Cellulose 2017, 24, 219-229.

[42] Zaarour, B.; Zhu, L.; Huang, C.; Jin, X. Controlling the Secondary Surface Morphology of Electrospun PVDF Nanofibers by Regulating the Solvent and Relative Humidity. Nanoscale Res. Lett. 2018, 13, DOI: 10.1186/s11671-018-2705-0.
[43] (a) De Vrieze, S.; Van Camp, T.; Nelvig, A.; Hagström, B.; Westbroek, P.; De Clerck, K. The effect of temperature and humidity on electrospinning. J. Mater. Sci. 2009, 44, 1357-1362; (b) Yang, G.-Z.; Li, H.-P.; Yang, J.-H.; Wan, J.; Yu, D.-G. Influence of Working Temperature on The Formation of Electrospun Polymer Nanofibers. Nanoscale Res. Lett. 2017, 12, 55.

[44] Weng, L.; Xie, J. Smart electrospun nanofibers for controlled drug release: recent advances and new perspectives. Smart electrospun nanofibers for controlled drug release: recent advances and new perspectives. Curr. Pharm. Design 2015, 21, 1944-1959.

[45] Liu, W.; Xi, G.; Yang, X.; Hao, X.; Wang, M.; Feng, Y.; Chen, H.; Shi, C. Poly(lactide-co-glycolide) grafted hyaluronic acid-based electrospun fibrous hemostatic fragments as a sustainable anti-infection and immunoregulation material. J. Mater. Chem. B 2019, 7, 4997-5010.

Received December 2, 2020 Accepted February 12, 2021 